\title{
A Novel Cholinergic "Slow Effect" of Efferent Stimulation on Cochlear Potentials in the Guinea Pig
}

\author{
T. S. Sridhar, ${ }^{1,2}$ M. C. Liberman, ${ }^{1,2,3,4}$ M. C. Brown, ${ }^{1,2,3}$ and W. F. Sewell ${ }^{1,2,4}$ \\ 'Eaton-Peabody Laboratory, Department of Otolaryngology, Massachusetts Eye and Ear Infirmary, Boston, \\ Massachusetts, 2Department of Otology and Laryngology, Harvard Medical School, Boston, Massachusetts, \\ ${ }^{3}$ Harvard-MIT Division of Health Sciences and Technology, Cambridge, Massachusetts, and ${ }^{4}$ The Program in \\ Neurosciences, Harvard Medical School, Boston, Massachusetts
}

This report documents slow changes in cochlear responses produced by electrical stimulation of the olivocochlear bundle (OCB), which provides efferent innervation to the hair cells of the cochlea. These slow changes have time constants of 25-50 sec, three orders of magnitude slower than those reported previously. Such "slow effects" are similar to classically described "fast effects" in that (1) they comprise a suppression of the compound action potential (CAP) of the auditory nerve, mirrored by an enhancement of the cochlear microphonic potential (CM) generated largely by the outer hair cells; (2) the magnitude of suppression decreases as the intensity of the acoustic stimulus increases; (3) they share the same dependence on OCB stimulation rate; (4) both are extinguished upon cutting the OCB; and (5) both are blocked with similar concentrations of a variety of cholinergic antagonists as well as with strychnine and bicuculline. These observations suggest that both fast and slow effects are mediated by the same receptor and are produced by conductance changes in outer hair cells. Slow effects differ from fast effects in that (1) fast effects are greatest for acoustic stimulus frequencies between 6 and $10 \mathrm{kHz}$, whereas slow effects peak for frequencies from 12 to $16 \mathrm{kHz}$, and (2) fast effects persist over long periods of OCB stimulation, whereas slow effects diminish after $60 \mathrm{sec}$ of stimulation. The time course of the slow effects can be described mathematically by assuming that each shock-burst produces, in addition to a fast effect, a small decrease in CAP amplitude that decays exponentially with a time constant that is long relative to the intershock interval. The long time constant of the slow effect compared to the fast effect suggests that it may arise from a distinct intracellular mechanism, possibly mediated by second-messenger systems.

[Key words: $\mathrm{ACh}$, cochlea, outer hair cell, olivocochlear efferents, in vivo pharmacology]

\footnotetext{
Received Aug. 9, 1994; revised Nov. 17, 1994; accepted Nov. 22, 1994.

A preliminary report was presented at the 17th Midwinter Meeting of the Association for Research in Otolaryngology. We are grateful to Frank Cardarelli, Mark Nilsen, Ishmael Stefanov-Wagner, Leslie Dodds, and Dan O'Grady for technical support and assistance. We thank Drs. J. C. Adams, B. Delgutte, J. J. Guinan, Jr., and E. Mroz for their advice and comments. This work was supported by grants from the NIDCD (DC00188, DC0076, DC00119, and DC01089).

Correspondence should be addressed to William F. Sewell, Eaton-Peabody Laboratory, Massachusetts Eye and Ear Infirmary, 243 Charles Street, Boston, MA 02111-3096

Copyright $@ 1995$ Society for Neuroscience 0270-6474/95/153667-12\$05.00/0
}

The presence of a prominent efferent innervation from the brainstem to the cochlea is well documented (reviewed by Warr, 1992). Anatomically, the olivocochlear bundle (OCB) comprises two major subsystems: one projecting via myelinated axons primarily to the outer hair cells (the medial olivocochlear, or MOC, system), and a second projecting via unnyelinated axons primarily to the dendrites of auditory nerve fibers in the area under the inner hair cells [the lateral olivocochlear (LOC) system] (Smith, 1961; Smith and Sjostrand, 1961; Kimura and Wersall, 1962; Warr and Guinan, 1979; Liberman, 1980; Brown, 1987).

Electrical stimulation of the OCB at the floor of the IVth ventricle causes suppression of sound-evoked auditory nerve discharge; this effect can be measured either by recording compound action potentials (Galambos, 1956) or single-fiber activity (Wiederhold and Kiang, 1970; Teas et al., 1970; Gifford and Guinan, 1983). Current evidence suggest that these suppressive effects are mediated by the MOC system; the peripheral effects of LOC activation remain unknown (Guinan et al., 1983; Gifford and Guinan, 1987). A large body of histochemical and pharmacological evidence has accumulated, indicating that the MOC system uses the neurotransmitter acetylcholine ( $\mathrm{ACh})$. The receptor on the outer hair cells that mediates the effects of $\mathrm{ACh}$ has an unusual pharmacological profile (Bobbin and Konishi, 1974; Guth et al., 1976; Kujawa et al., 1994), but it appears to be more similar to other nicotinic than to muscarinic receptors in that it contains an ion channel (Housley and Ashmore, 1991; Fuchs and Murrow, 1992; Erostegui et al., 1994).

The time course of OCB-mediated suppression has been studied by Wiederhold and Kiang (1970), who recorded from cat auditory nerve fibers while stimulating the OCB. They demonstrated that suppression (1) builds up to its maximum level within 100 msec after shock-train onset, (2) can be maintained for many minutes with continued OCB stimulation, and (3) dissipates exponentially over $100 \mathrm{msec}$ after shock-train offset. In the course of our studies on the pharmacology of this efferent synapse in the guinea pig, we noted that the effect of OCB stimulation on the round-window potentials included "slow" suppressive effects that waxed and waned with a decay time constant several orders of magnitude greater than those previously reported.

In the present report, we summarize results from a series of physiological experiments designed to characterize the basic features of these slow effects, and a series of pharmacological studies designed to determine whether the classic fast effects and these novel slow effects are mediated by the same receptor. An- 


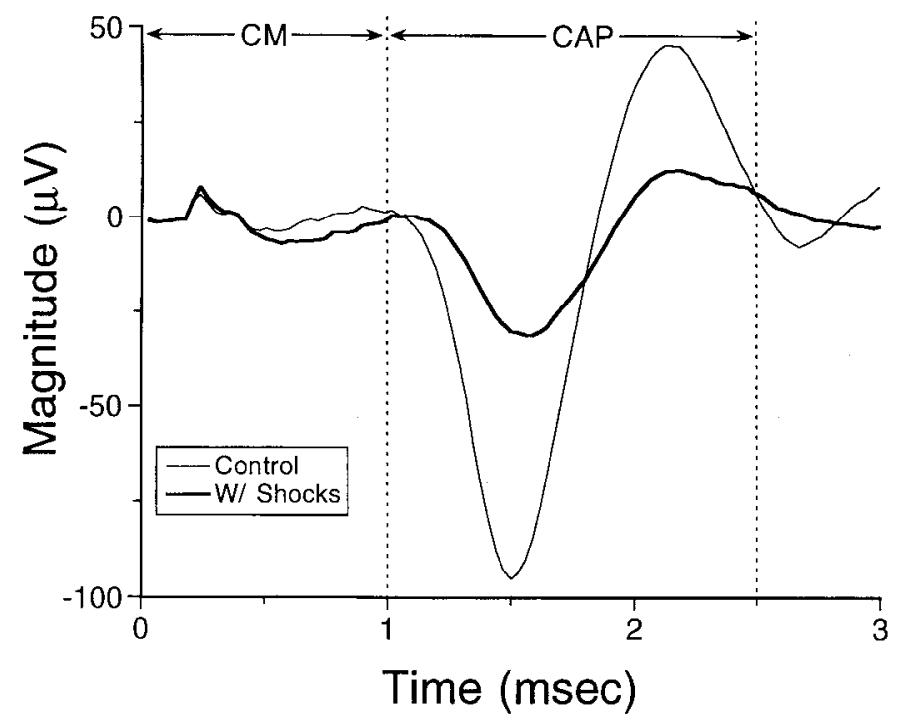

Figure 1. Waveform of the cochlear microphonic and compound action potential in response to an acoustic click. Shown are a control response to a click, and a response to a click presented $10 \mathrm{msec}$ after a train of shocks to the OCB. Arrows delineate time windows within which the peak-to-peak amplitudes of the CM and CAP were measured. The difference in amplitude of the two waveforms is a measure of the fast effect of OCB stimulation, showing enhancement of CM and suppression of CAP. Click level was $20 \mathrm{~dB}$ above threshold.

tagonists examined included three nicotinic blockers (curare, decamethonium, and hexamethonium), two muscarinic blockers [atropine, a broad spectrum blocker, and 4-diphenylacetoxy- $N$ methylpiperidine (4-DAMP), an M3 receptor blocker], strychnine (an atypical cholinergic antagonist), and bicuculline (a GABA antagonist shown to block the effects of $\mathrm{ACh}$ on hair cells) (Erostegui et al., 1994; Kujawa et al., 1994).

\section{Materials and Methods}

In our preparation, efferent fibers to the cochlea were electrically stimulated in the brainstem while responses reflecting the summed activity of hair cells and auditory nerve fibers were recorded from the inner ear (Brown et al., 1983: Gifford and Guinan, 1983, 1987). Albino guinea pigs of either sex, weighing between $350-600 \mathrm{gm}$, were anesthetized with Nembutal $(15 \mathrm{mg} / \mathrm{kg}$, i.p.) and Innovar-Vet $(0.4 \mathrm{ml} / \mathrm{kg}$, i.m.), or with urethane (1.5 g/kg, i.p.) and Innovar-Vet $(0.25 \mathrm{ml} / \mathrm{kg}$, i.m.). The animals received boosters of urethane (1/3 the original dose) after $6-8$ $\mathrm{hr}$, and boosters of Innovar-Vet and Nembutal (1/3 the original dose) cvery $2 \mathrm{hr}$. Animals were tracheostomized and connected to an artificial respirator. The temperature within the experimental chamber was maintained at $32-33^{\circ} \mathrm{C}$. A heating blanket was used to maintain the rectal temperature of the animal between $37-39^{\circ} \mathrm{C}$. The pinnae were removed, and the cochlea was exposed by a dorsolateral approach. Middle-ear muscles were inactivated for some experiments by exposing and severing their innervation in the epitympanic space. Acoustic stimuli were produced by a 1 inch condenser microphone driven as a sound source and were measured on line by a 1/4 inch microphone and probe tube assembly housed in a brass coupler that sealed tightly around the cartilaginous portion of the external ear (Kiang et al., 1965).

To measure the compound action potential and cochlear microphonic, gross electric potentials that represent the summed activity of the auditory nerve fibers and the outer hair cells, respectively, a silver-wire electrode was placed near the round window and an indifferent clectrode was connected to the tongue or placed in the neck muscles. Responses to acoustic stimuli (see below) were amplified 10,000 times by an AC-coupled amplifier (bandpass $100-10,000 \mathrm{~Hz}$ ). The resulting signal was digitized with $30 \mu \mathrm{sec}$ sampling interval via a 12 -bit $\mathrm{A} / \mathrm{D}$ converter (National Instruments A2000), and the digital waveforms were averaged on line using custom software in LabView II (National Instruments) on a Macintosh computer. A posterior craniotomy was per-

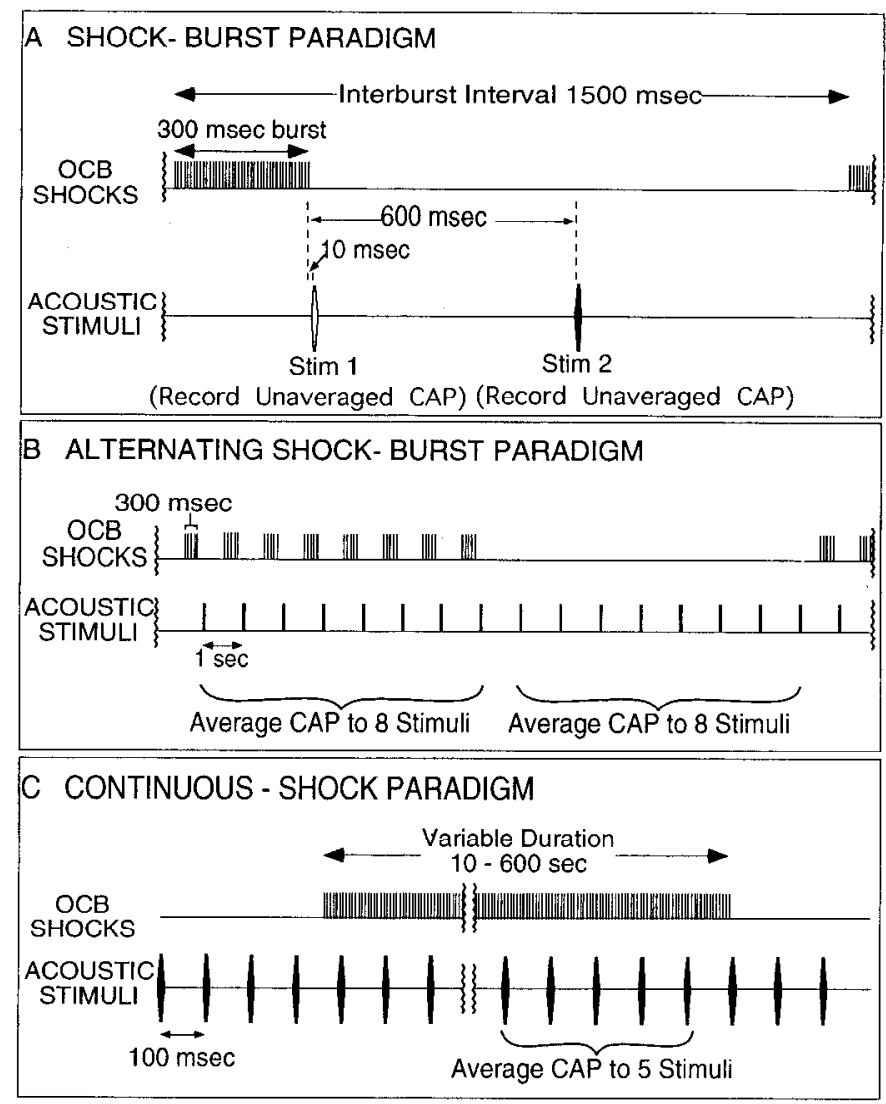

Figure 2. Three different paradigms for measuring the fast and slow effects of olivocochlear stimulation. See Materials and Methods for details.

formed, and a portion of the cerebellum was aspirated to expose the floor of the IVth ventricle. The OCB was stimulated electrically with electrodes placed on the floor of the IVth ventricle at the midline, where the OCB runs close to the surface of the brainstem (White and Warr, 1983). The stimulator consisted of a rake of six fine, silver wires placed at $0.5 \mathrm{~mm}$ intervals. After placement of the rake along the brainstem midline, different pairs of electrodes were assayed to find the optimum pair for eliciting OC activity. Shocks were always monophasic pulses of $150 \mu \mathrm{sec}$ duration. Shock levels were typically set $5-10 \mathrm{~dB}$ above threshold for facial twitches in the absence of the paralytic. To section the $\mathrm{OCB}$, a rostrocaudal incision was made along the lateral border of the floor of the IVth ventricle (Liberman, 1990). Since electrical stimulation of the OCB can cause muscle twitches, muscle paralysis was induced with $d$-tubocurarine $(1.25 \mathrm{mg} / \mathrm{kg}, \mathrm{i} . \mathrm{m}$.) and maintained with boosters as necessary. OCB-induced changes in cochlear microphonic and compound action potentials were determined from digitized waveforms such as those illustrated in Figure 1.

Three different protocols were used in studying the effects of OCB stimulation and are illustrated in Figure 2. The protocols differed in the timing and the number of both shocks and acoustic stimuli. The alternating shock-burst paradigm (Fig. $2 B$ ) was used in experiments to examine the pharmacology of efferent stimulation, where the slow effect was first noticed. The slow effect was physiologically characterized with the shock-burst paradigm (Fig. $2 A$ ) and with the continuous-shock paradigm, which gave better temporal resolution of the effect and had very different duty cycles. We continued to use the alternating shock-burst paradigm in the pharmacological experiments since we had already collected considerable data with that protocol. Acoustic stimuli for all paradigms were clicks (100 $\mu \mathrm{sec}$ duration) or tone pips (4 msec duration, $0.5 \mathrm{msec}$ rise-fall times, $\cos ^{2}$ shaping), and were typically presented at 20-30 dB above visual detection threshold for the compound action potential.

In the shock-burst paradigm (Fig. 2A), a burst of OCB shocks (300/ $\mathrm{sec}$ for $300 \mathrm{msec}$ ) was presented every $1.5 \mathrm{sec}$. A pair of acoustic stimuli was presented so that the first was $10 \mathrm{msec}$, and the second 600 
The Journal of Neuroscience, May 1995, 15(5) 3669

msec, after the end of each shock burst. An unaveraged CAP waveform was obtained in response to each stimulus presentation, and the peakto-peak amplitude computed. Control responses (with no shocks) were measured before, and for at least $1 \mathrm{~min}$ after, the train of shock bursts.

In the alternating shock-burst paradigm (Fig. $2 B$ ) used for pharmacological experiments, a burst of OCB shocks (300/sec for $300 \mathrm{msec}$ ) was presented every second. Acoustic stimuli (tone pips or clicks) were presented $10 \mathrm{msec}$ after the end of each burst. An averaged CAP waveform was obtained (and the peak-to-peak amplitude computed) in response to eight such clicks, and this amplitude was compared with that obtained in response to eight clicks presented without OCB shocks. These two CAP measures (with and without OCB shocks) constituted one cycle of the paradigm, and the cycle was repeated five times during one run. Successive runs were separated by intervals of approximately $3.5 \mathrm{~min}$, during which there was neither acoustic nor OCB stimulation.

In the continuous-shock paradigm (Fig. 2('), OCB shocks were presented at $150-300 / \mathrm{sec}$ for a period of $10-600 \mathrm{sec}$; the pre- and postshock trial periods lasted between 30 and $300 \mathrm{sec}$. Acoustic stimuli were presented every $100 \mathrm{msec}$ continuously, and CAP waveforms (averaged from responses to five such stimuli) were obtained every second. During OCB stimulation, large shock artifacts in the round-window response were eliminated by discarding individual waveforms from the average if the peak-to-peak amplitude exceeded the control CAP amplitude by more than $20 \%$.

For pharmacological experiments designed to block the cholinergic receptor at the outer hair cells, drugs were perfused through the scala tympani space of the cochlea. An inlet perfusion hole was drilled in the cochlea just apical to the round window with a $0.25 \mathrm{~mm}$, hand-held pivot drill. After an additional ventral opening was made in the bulla, an outlet perfusion hole in the apex of the cochlea was pricked with a right-angle pick. Only those animals in which cochlear thresholds remained within $20 \mathrm{~dB}$ of the predrilling values are included in this report. The perfusion pipette (a 31 gauge, stainless steel cannula) was placed in the basal hole and artificial perilymph (composition: $120 \mathrm{mM} \mathrm{NaCl}$, $3.5 \mathrm{~mm} \mathrm{KCl}, 1.5 \mathrm{mM} \mathrm{CaCl}_{2}, 5.5 \mathrm{~mm}$ glucose, $20 \mathrm{~mm}$ HEPES; titrated with $\mathrm{NaOH}$ to $\mathrm{pH} 7.5$; total $\mathrm{Na}^{+}=130 \mathrm{~mm}$ ) was infused by a peristaltic pump at $5 \mu \mathrm{l} / \mathrm{min}$. (In three experiments, the flow rate was $15 \mu \mathrm{l} / \mathrm{min}$.) Since the seal between the pipette tip and the hole in the scala tympani was not leak proof, the actual perfusion rate was less than the flow rate. During the perfusion, the middle-ear cavity was drained with a gauze pad. All pharmacological agents [atropine sulfate, 4-DAMP methiodide, $d$-tubocurarine chloride, hexamethonium dichloride, (-)-bicuculline methiodide, and strychnine hydrochloride] were obtained from Research Biochemicals Inc. (Natick, MA), except for decamethonium bromide, which was obtained from Sigma Chemical Co. (St. Louis, MO). The antagonists were dissolved in artificial perilymph and loaded into a loop; by turning a valve, the flow of the artificial perilymph could be diverted through the loop containing the drug, thus eliminating any mechanical artifact associated with drug application. Based upon injections of dye, the lag between the opening of the valve and the arrival of drug at the ear was $10 \mathrm{~min}$. This was due to a fluid dead space between the valve and the inlet hole in the cochlea of about $50 \mu l$. Maximal concentrations of dye were not achieved until $13 \mathrm{~min}$, presumably due to laminar flow at the leading edge of the injectate. The earliest discernible effect of drugs was typically about $15 \mathrm{~min}$. This additional $2-5 \mathrm{~min}$ was probably attributable to perfusion time through the scala tympani and to diffusion time through the organ of Corti.

Drugs were perfused through the scala tympani in increasing concentration until maximal effects were noted and then washed out with artificial perilymph. In some experiments it was possible to test the effect of more than one drug on the same cochlea. Dose-response curves were obtained by measuring the suppression magnitudes for each dose and comparing them to baseline levels, defined as the mean of measurements made for $25 \mathrm{~min}$ before the first dose reached the cochlea. To ensure that the measure of response blockade reflected the maximal effect for a particular dose, only the last data point obtained before the next higher drug concentration reached the cochlea was used.

Response blockade for each drug at each dose was averaged from a number of animals $(n \geq 4)$, and the following sigmoidal curve was fit to the data:

$$
y(D)=y_{\max }\left[1 / 1+\left(\mathrm{EC}_{50} / D\right)^{n}\right],
$$

where $y(D)$ is the percentage response blockade due to antagonist application at concentration $D$, and $y_{\max }$ is the maximal response. The $\mathrm{EC}_{50}$ is the antagonist concentration required to produce a $50 \%$ block of efferent effects, and $n$ is a factor describing the steepness of the doseresponse curve (Patneau and Mayer, 1990). Fits were obtained using KALEIDAGRAPH software (Press et al., 1988).

\section{Results}

\section{Demonstration of slow effects with different patterns of $O C$} stimulation

The effect of electrical stimulation of the OCB is to suppress the CAP of the auditory nerve (Fig. 1). Other studies have reported that the onset and offset time constants for OC-mediated suppression are about $60 \mathrm{msec}$ (Wiederhold and Kiang, 1970). The distinction between these classic "fast" effects of OCB activation and the novel "slow" effects is illustrated in Figure 3 using three different experimental paradigms (see Fig. 2 and Materials and Methods).

In one paradigm (Fig. $3 A$ ), a burst of OCB shocks was presented every $1.5 \mathrm{sec}$. After each shock burst, two identical tone pips were presented. The first (pip 1) was within a fraction of the decay time constant for OCB fast effects. Pip 2 occurred much later, at a time equivalent to approximately 10 decay time constants of the fast effect. Thus, based on existing descriptions of OC-mediated suppression, there should have bcen a reduction in pip-1 CAP after the first shock-burst and no change in pip-2 CAP. This was, in fact, observed, but only for the first few shock-burst presentations. After several shock bursts had been presented, a steady decrease in the response to both pip 1 and pip 2 began to appear; after the shocks were terminated, a lingering suppression of the CAP was seen and amplitudes did not return to preshock control values for about $90 \mathrm{sec}$. These are two manifestations of the "slow" effects of OCB stimulation.

Similar slow effects were seen when the OCB was stimulated intermittently. In the alternating shock-burst paradigm (Fig. 3B), sets of eight shock bursts were interleaved with $8 \mathrm{sec}$ "control" periods without OCB stimulation. The CAP amplitude during these control periods (open circles in Fig. $3 B$ ), as well as the CAP evoked while shocking the OCB (filled circles), gradually decreased as each set of shock bursts was presented. There was also a lingering suppression of $\mathrm{C} \Lambda \mathrm{P}$ amplitude for as long as $100 \mathrm{sec}$ after the last set of shocks.

The same slow-onset and slow-offset suppression was seen when the OCB was stimulated continuously. In the continuousshock paradigm (Fig. 3C), tone-pip CAP was monitored before, during, and after a continuous train of OCB shocks lasting for $60 \mathrm{sec}$. There was an immediate CAP reduction in the first measurement taken after shock-train onset (each CAP measure required about $1 \mathrm{sec}$ to acquire; thus, the fast-effect onset appears immediate). As with the other two paradigms, there was a slow decrease in CAP amplitude during the OCB stimulation for at least $40 \mathrm{sec}$ after shock-train onset and a lingering suppression of CAP amplitude after shock-train offset that required at least $90 \mathrm{sec}$ to disappear.

The slow effects of OCB stimulation on CAP illustrated in Figure 3 were robust in the sense that they were clearly demonstrable in every guinea pig tested, which included 26 animals examined with the shock-burst paradigm, 46 animals with the alternating shock-burst paradigm, and 20 animals with the continuous-shock paradigm. However, shocks delivered at the floor of the IVth ventricle could have other effects besides activation of the $O C B$, including direct effects on the cochlea itself. To test whether slow effects are, indeed, mediated by the OC pathway, fast and slow effects were measured bilaterally in five animals in which the OCB to one ear was sectioned by a lateral 

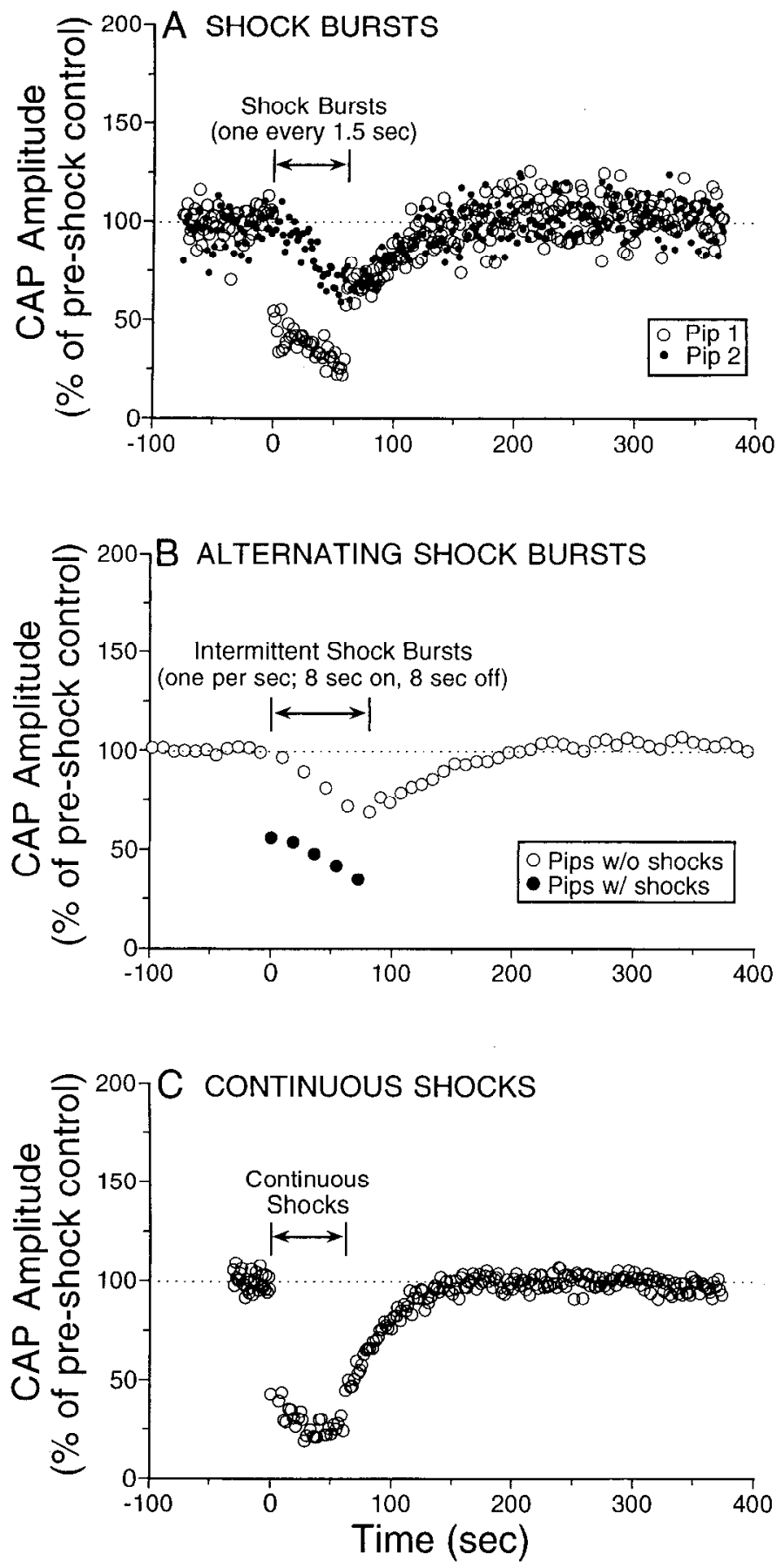

Figure 3. Fast and slow effects on CAP amplitude during OCB stimulation as seen in the three paradigms illustrated in Figure 2 and described in Materials and Methods. A, Shock bursts were presented. The fast effect is seen as the amplitude difference between pip 2 and pip 1 . The slow effect is seen as the steady decrease in the responses to both pips. $B$, Alternating shock bursts were presented. The fast effect is seen as the amplitude difference between the pips without shocks and the pips with shocks. The slow effect is seen as the steady decrease in the response to both pips. $C$, Continuous shocks were presented. The fast effect is seen as the immediate decrease in CAP amplitude and the slow effect is seen as the slow decrease in amplitude. All acoustic stimuli were tone pips at $14.5 \mathrm{kHz}$ presented $25-30 \mathrm{~dB}$ above threshold. For all panels, the vertical axis (peak-to-peak CAP amplitude) is normalized to the average value for all measures before the first OCB shocks. incision in the floor of the IVth ventricle. As illustrated in Figure 4 , unilateral interruption of the OCB extinguished both slow and fast effects on the de-efferented side (Fig. $4 B$ ) while not affecting responses on the intact side (Fig. $4 A$ ). In eight animals, we further demonstrated that middle-ear muscle activation was not involved in the generation of slow effects, since slow effects were unaffected by surgical inactivation of the muscles (data not illustrated).

One possible explanation for these slow effects is that $\mathrm{OC}$ fibers slowly increased their rate of discharge during and after repeated electrical stimulation of the brainstem due to effects (either direct or indirect) at their cell bodies in the brainstem. To test this hypothesis, one experiment was performed (using the alternating shock-burst paradigm) in which the OCB was sectioned immediately after the last burst of shocks. As illustrated in Figure $4 C$, an initial "control" run (open circles) showed that the slow effects were within the normal range in this animal. In a second run of the paradigm (crosses), the OCB was sectioned immediately after the last shock burst. The magnitude of the lingering suppression of CAP and the time required for recovery were not fundamentally different from that seen in the control run. In a final run (not illustrated) the completeness of the OCB cut was demonstrated: fast and slow effects of the OCB shocks had disappeared. These data show that the slow effects are not due to changes in the excitability or resting discharge of $\mathrm{OC}$ neurons.

\section{Decrement and overshoot of the slow effect}

For the measurements illustrated in Figure 3, the total elapsed time from the first to the last OCB shock was $60-80 \mathrm{sec}$. This shock-train duration maximizes the size of the slow effects. As shown in Figure $5 A$, when electrical stimulation was prolonged beyond $60-80 \mathrm{sec}$, slow effects began to decline: the CAP amplitudes to both pip 1 and pip 2 recovered in the face of continued shock-burst presentation, and the lingering suppression after the last shock burst was significantly less (compare Figs. $3 A$, $5 A$ ). Although slow effects of OCB stimulation appeared to wax and wane in the face of continued OCB stimulation, the fast effect, that is, the difference in CAP amplitude to pip 1 and pip 2 of any given stimulus pair, remained nearly constant throughout. Similar trends can be seen in the data obtained in the alternating shock-burst paradigm (Fig. $5 B$ ) and in the continuousshock paradigm (Fig. $5 C$ ). In all three cases, the decrement of the slow effect is seen as (1) a slow recovery in the magnitude of the CAP during the OCB stimulation after a minimum was reached 60-90 sec after the shock-train onset, and (2) a decreased magnitude of the lingering suppression after shock-train offset.

During the recovery phase after shock-train offset, there can be an overshoot in CAP amplitude, that is, the mean CAP amplitude can be larger than that seen before the first shock burst. Such an overshoot is especially clear in the data in Figure 6: the postshock CAP amplitudes were markedly higher than control values for a period of about $100 \mathrm{sec}$ after the recovery phase following the last shock burst. Signs of elevated CAP amplitudes could last for as long as 5 min after shock-train offset and could represent as much as a $25 \%$ increase over preshock values. Figure 6 illustrates a case where the overshoot was especially large. However, the phenomenon is discernible in some of the other figures (e.g., Figs. $3 A, 4 C, 5 A$ ): compare average CAP amplitude in the control period to that seen $100-200 \mathrm{sec}$ after the shock bursts end. The overshoot phenomenon was a less constant fea- 

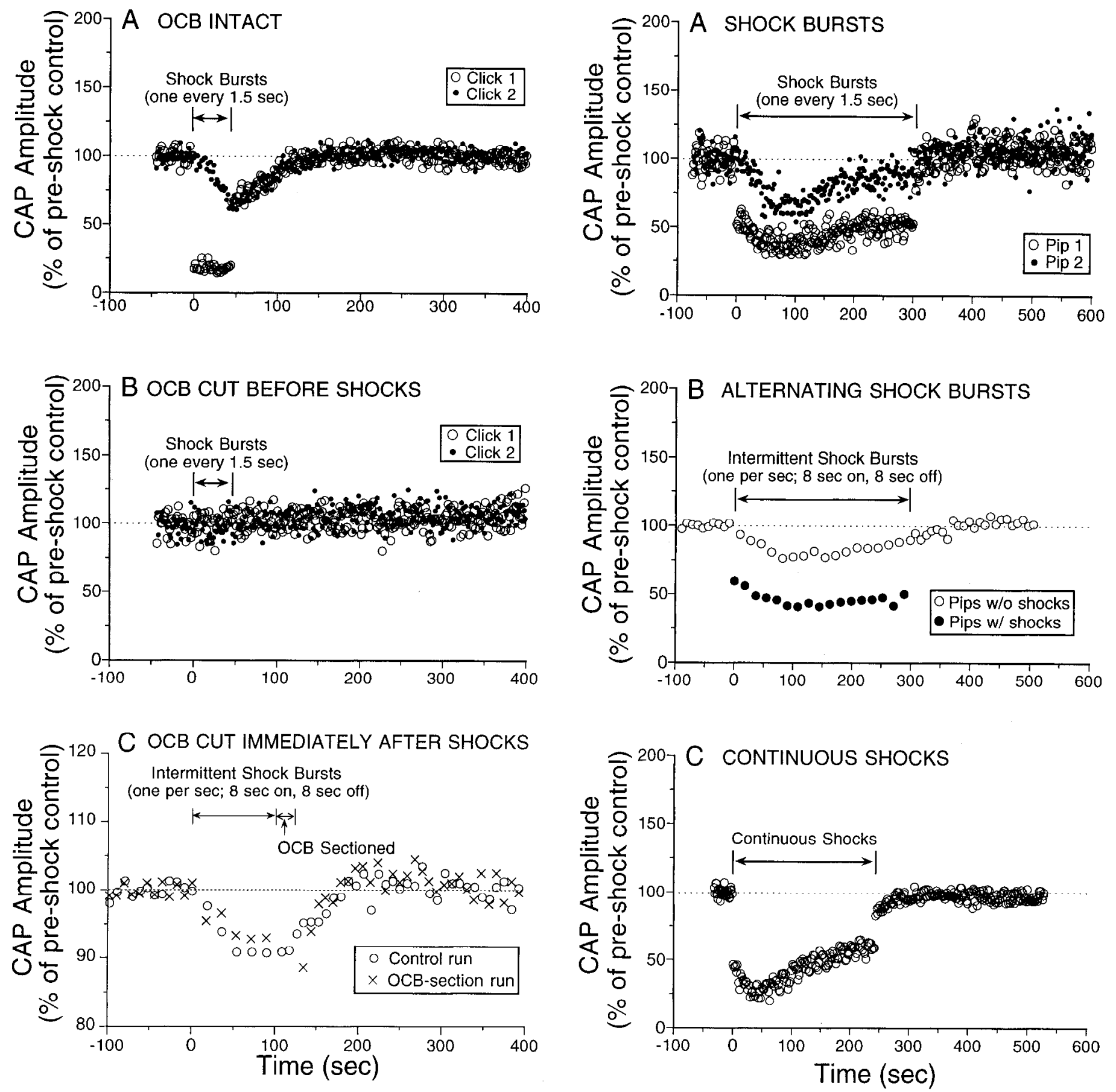

Figure 4. Sectioning the OCB climinatcs both fast and slow effects of OCB shocks, but only if performed before the shocks are presented. Data in $A$ and $B$ are from the left and right ears of one animal in which the OCB was cut to one side, before the OCB shocks were presented. Data in $A$ and $B$ represent consecutive runs obtained 12 min apart without moving the OCB stimulator. Data points in both panels represent normalized CAP responses to pairs of low-level clicks (roughly $10 \mathrm{~dB}$ above threshold) as seen in the shock-burst paradigm described in Figure $2 A$. Data in $C$ are from a different animal in which the $O C B$ was cut immediately after cessation of the shocks, during one run of the alternating shock-burst paradigm. The time course of the recovery of CAP was unchanged after cutting the $O C B$, indicating that the recovery of the slow effect was independent of OCB input. The acoustic stimuli were tone pips at $14 \mathrm{kHz}, 20 \mathrm{~dB}$ above threshold.

Figure 5. Fast and slow effects on CAP amplitude seen during several minutes of OCB stimulation for the three experimental paradigms illustrated in Figure 2. The acoustic stimuli were tone pips at $14.5 \mathrm{kHz}$ in $A$ and $B$, and $16 \mathrm{kHz}$ in $C$. All stimuli were presented at $25-30 \mathrm{~dB}$ above threshold. All other aspects of data collection and display are as described for Figure 3.

ture of our data than the slow suppressive effect on CAP described above. Although our data are limited, it is clear that the size of the overshoot was not proportional to the size of the slow suppression that preceded it.

Similarities and differences between fast and slow effects

Classic fast effects of OCB stimulation on round window potentials are known to comprise, in addition to suppression of the 


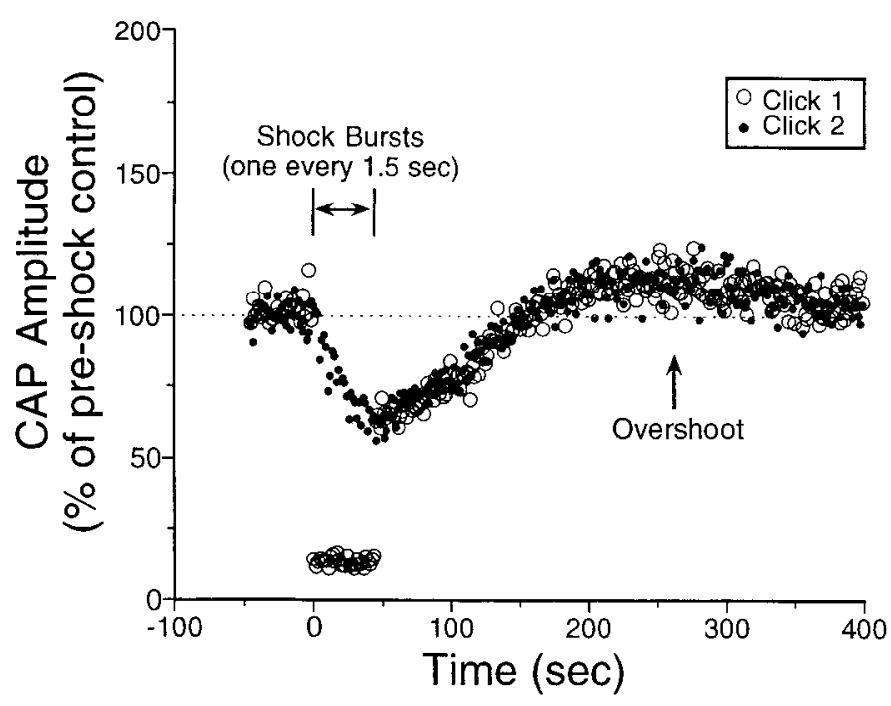

Figure 6. Overshoot in CAP amplitude after 30 shock bursts were presented to the OCB using the paradigm illustrated in Figure $2 A$. Acoustic stimuli were clicks presented at about $20 \mathrm{~dB}$ above threshold.
CAP, an enhancenent of the cochlear microphonic (CM) (Fex, 1959; Wiederhold and Peake, 1966), which reflects the summed receptor potentials of outer hair cells (Dallos, 1973; Russell and Sellick, 1983). To look for slow effects of OCB stimulation on the CM, we used moderate-level, $100 \mu$ sec clicks, which allowed CM and CAP to be distinguished based on response latency (Fig. 1). In Figure 7, both a fast CM enhancement and a fast CAP suppression can be seen as the difference in response amplitudes to click 1 and click 2 of each stimulus pair. There was also a slow enhancement of the $\mathrm{CM}$ that mirrored the slow suppression of the CAP (seen for CM and CAP amplitudes in response to click 2 ).

Another classic feature of fast effects is that the magnitude of response suppression decreases as the level of the acoustic stimulus increases (Wiederhold, 1970). As illustrated in Figure 8A, the slow and fast effects demonstrated a similar dependence on stimulus level. For the slow effect, the average suppression magnitude decreased from about $20 \%$ to less than $10 \%$ as click level rose from about $10 \mathrm{~dB}$ above threshold ( $70 \mathrm{~dB}$ attenuation) to levels $40 \mathrm{~dB}$ higher. Over the same stimulus level range, the fast-effect magnitude from the same set of measurements also decreased by about a factor of 2 .

Another stimulus parameter known to affect the magnitude of the fast effect is the rate at which the OCB is shocked: shock

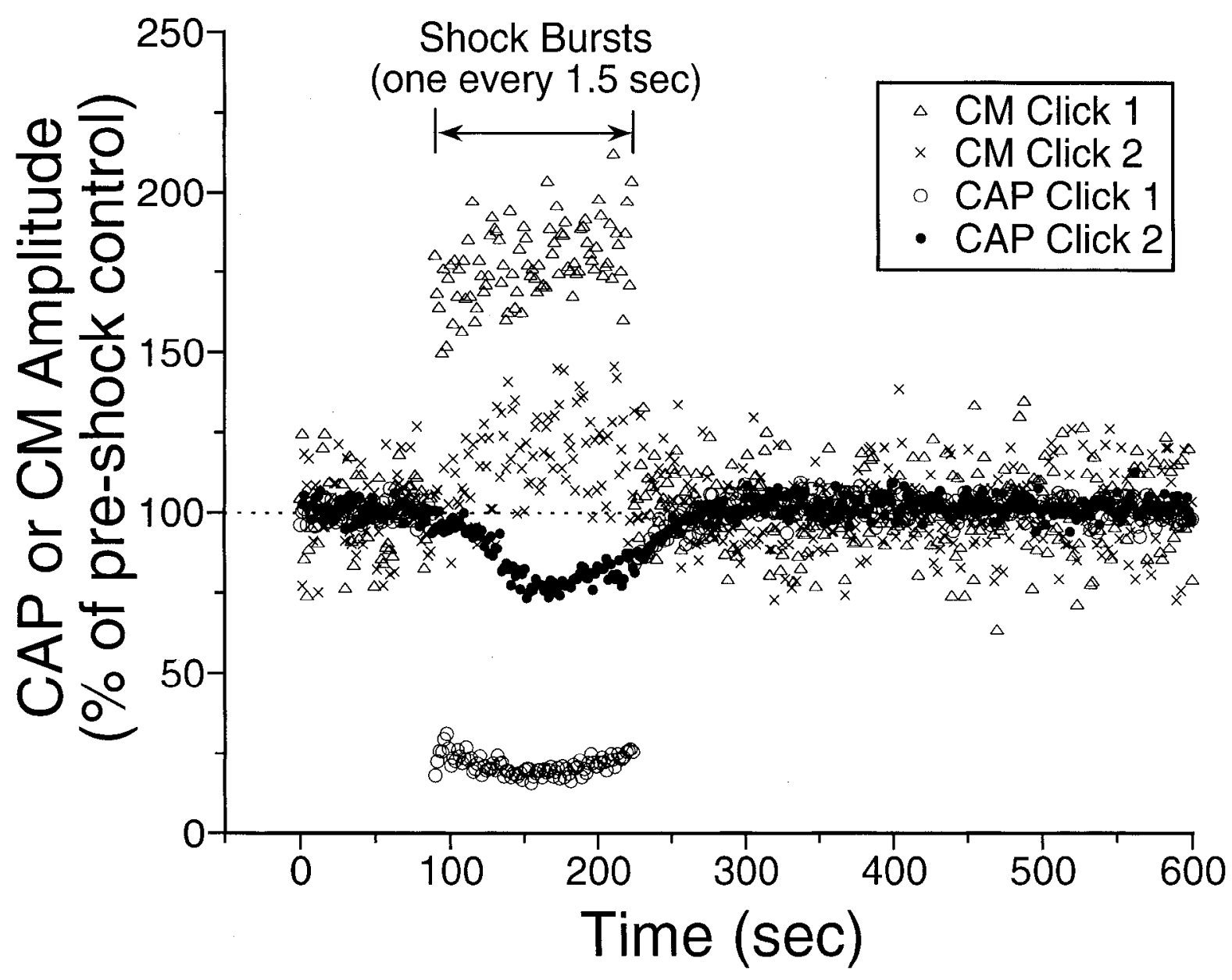

Figure 7. Slow and fast effects of OCB stimulation on the cochlear microphonic $(C M)$ and the CAP, measured simultaneously. The paradigm used is the same as that described in Figure 2A, except that for each acoustic stimulus, the peak-to-peak amplitude of the CM and CAP are measured separately: the stimuli were clicks (presented roughly $20 \mathrm{~dB}$ above threshold), and the CM and CAP were separated according to response latency (Fig. 1). 

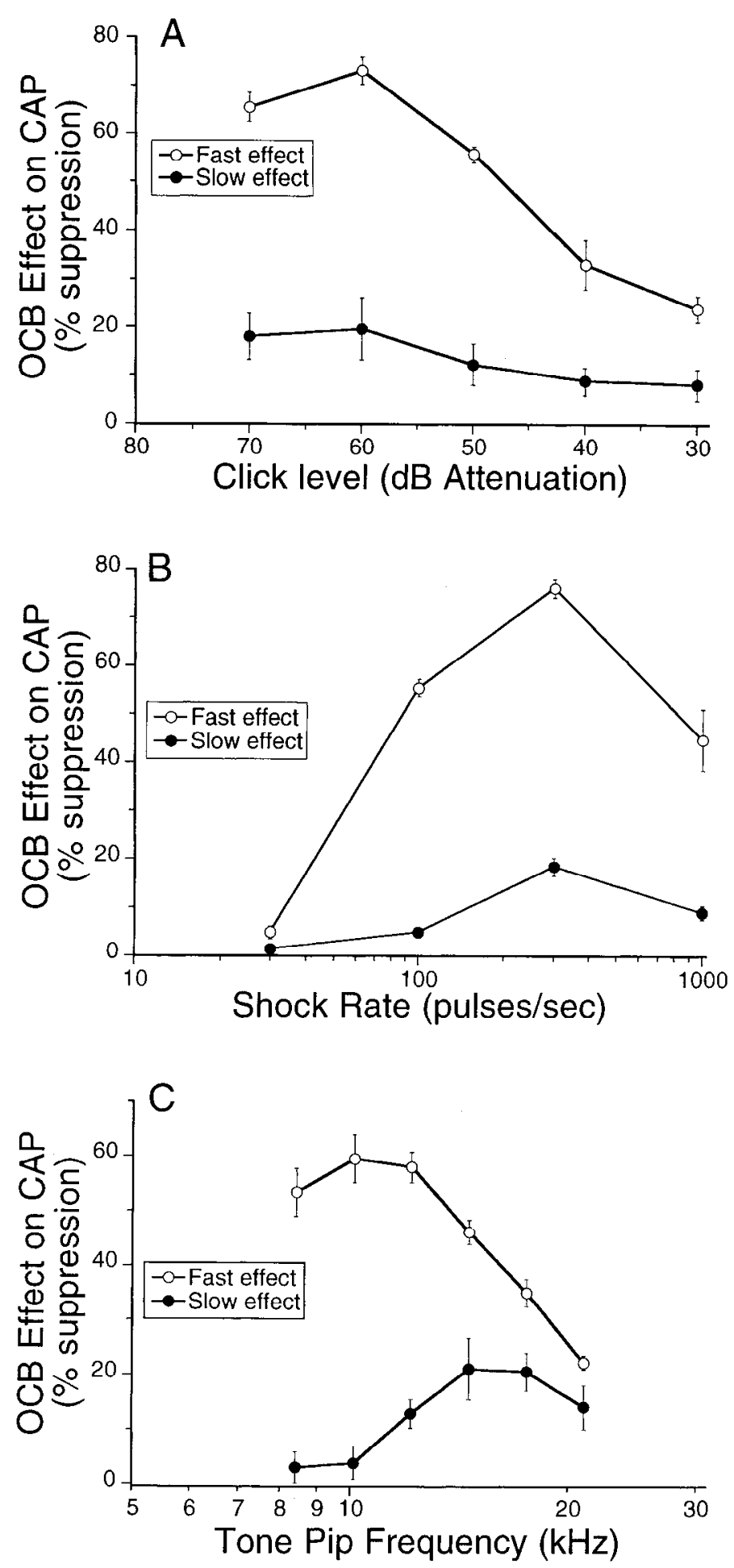

Figure 8. Comparison of fast and slow effect magnitude as a function of stimulus level $(A)$, shock rate $(B)$, and stimulus frequency $(C)$. $A$, These data represent average values for four animals ( \pm standard error), collected using a variant of the shock-burst paradigm illustrated in Figure $2 A$ : click level was changed between each pair of clicks, stepping through five levels, and then repeating the sequence. For each animal tested, the fast effect was measured by averaging, for all the responses at a given click intensity when the shock bursts were present, the difference in CAP magnitudes to the first versus the second pips of each stimulus pair:

$$
\% \text { suppression }=\left(1-\mathrm{CAP}_{1} / \mathrm{CAP}_{2}\right) * 100
$$

The slow effect is measured by computing, for all the responses, the difference between the average CAP amplitude to the second pip of rates of $200-400 / \mathrm{sec}$ produce maximal suppression (Desmedt, 1962; Wiederhold and Peake, 1966; Gifford and Guinan, 1987). As shown in Figure $8 B$, varying shock rate affected both fast and slow components similarly, with maximal effects seen at a shock rate of $300 / \mathrm{sec}$.

One important way in which the magnitude of the fast and slow effects differed was in their dependence on the frequency of the acoustic stimulus. As has been demonstrated by others, the largest fast effects are seen for responses from cochlear regions tuned to frequencies between about 6 and $10 \mathrm{kHz}$, with effects decreasing monotonically for cochlear regions apical and basal to those locations (Guinan and Gifford, 1988). Such a magnitude versus frequency distribution corresponds well to the distribution of MOC terminals on outer hair cells as a function of cochlear location (Liberman et al., 1990). As illustrated in Figure $8 C$, when the frequency of tone pips was varied from 8 to $21 \mathrm{kHz}$, the largest fast effects were in the $8-10 \mathrm{kHz}$ region as expected; however, the simultaneously measured slow effects were minimal for stimulus frequencies lower than $10 \mathrm{kHz}$ and showed a prominent peak at about $14 \mathrm{kHz}$.

\section{Mathematical description of slow effects}

In order to quantify the time course and magnitude of the slow effect, a mathematical description of the slow effect was tit to the data. This allowed an accurate measure of the time constant of the decay of the slow effect and a comparison of the magnitude of the slow effect associated with each shock burst to that of the fast effect. These parameters are not easily determined by visual inspection of the data. The equations assume that each shock burst produced, in addition to a fast suppression of CAP amplitude that decays rapidly, a small decrease in CAP amplitude that decays exponentially with a time constant that is long relative to the shock repetition rate. A delay was added between the onset of each shock burst and the onset of the slow effect. The set of equations has three free parameters: (1) the time constant of the decay of the slow effects, (2) the asymptotic suppression of the CAP, which reflects the magnitude of the slow

$\leftarrow$

each pair compared to the average CAP amplitude during the preshock control period:

$$
\% \text { suppression }=\left(1-\mathrm{CAP}_{2} / \mathrm{CAP}_{\mathrm{con}}\right) * 100
$$

$B$. Dependence of fast and slow effect on shock rate for the alternating shock-burst paradigm illustrated in Figure $2 B$. For this paradigm, the fast-effect measure compares the control CAP amplitude (no OCB shocks) on the first of five trials to the CAP amplitude with OCB shocks on the same trial:

$$
\% \text { suppression }=\left(1-\mathrm{CAP}_{\text {orR-1}} / \mathrm{CAP}_{\text {commiral }-1}\right) * 100
$$

The slow effect measure compares the control CAP amplitude (without OCB shocks) for trial 1 versus trial 5:

$$
\% \text { suppression }=\left(1-\mathrm{CAP}_{\text {control-5 }-5} / \mathrm{CAP}_{\mathrm{comirol}-1}\right) * 100
$$

The acoustic stimuli were clicks $20 \mathrm{~dB}$ above threshold. The duration of shock bursts was maintained constant at $300 \mathrm{msec}$ and the rate was stepped from 30 to $1000 \mathrm{pulses} / \mathrm{sec}$. Three such cycles were done in each animal. Each data point represents the mean value $( \pm$ standard error) from four animals. $C$, Magnitude of fast and slow effects as a function of tone-pip frequency, at sound pressure levels roughly $30 \mathrm{~dB}$ above threshold. Data were obtained in a way analogous to that described for $A$, except that tone pips were used as the acoustic stimuli, and the tone pip frequency was changed between each pair of tone pips, stepping systematically through the six values (from 8 to $21 \mathrm{kIIz}$ ) displayed in the figure and then repeating the sequence. Data are mean and standard error from four animals. 


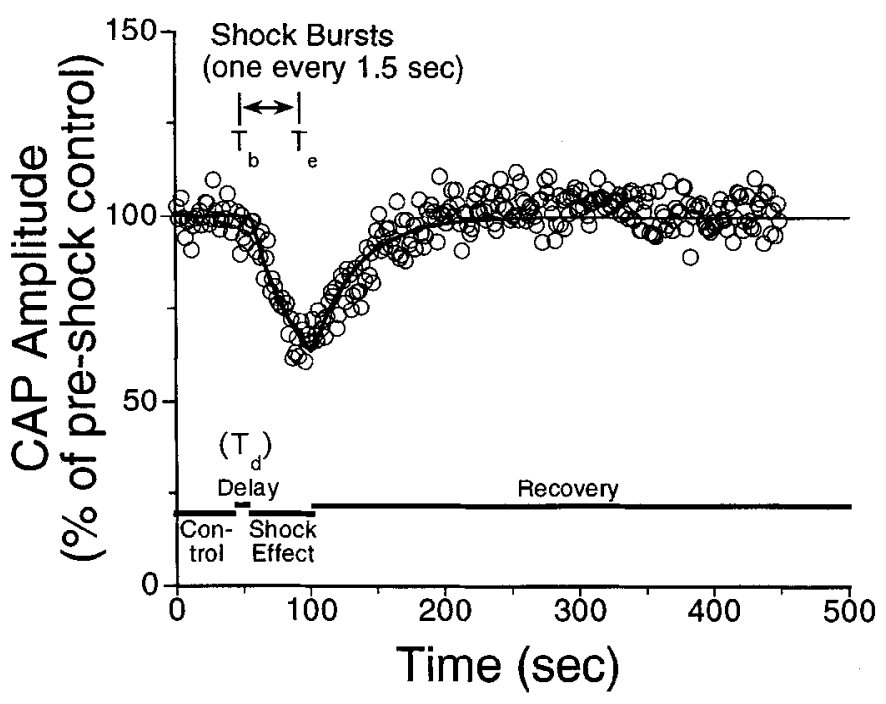

Figure 9. Data from a mathematical description of the time course of the slow effect (solid line) fit reasonably well to CAP datit (open circles) collected using the shock-burst paradigm with clicks as the acoustic stimulus (presented $20 \mathrm{~dB}$ above threshold). It assumed that each shock burst produced, in addition to the fast effect, a slow effect of relatively small magnitude, but with a long decay time constant relative to the stimulus repetition rate. This led to a gradual build up of the magnitude of the slow effect. The curve was fit by computing a value of $y$ for each time point such that the least squares difference between the data points and the computed points was minimized. The following set of equations were fit to the data:

for $t<T_{b}+T_{d}$,

$$
y(t)=C
$$

for $t<T_{e}+T_{d}$,

$$
y(t)=C-a\left(1-e^{-\alpha\left[t-\left(T_{\mathrm{b}}+T_{\mathrm{d}}\right)\right]}\right)
$$

for $t>T_{e}+T_{d}$,

$$
y(t)=C-\left[a\left(1-e^{-\alpha\left[t-\left(T_{\mathrm{b}}+T_{\mathrm{d}} \mathrm{j}\right)\right.}\right)\right]\left[e^{-\alpha\left(t+\left[T_{\mathrm{e}}+T_{\mathrm{d}} \mathrm{j}\right)\right.}\right] ;
$$

$T_{b}$ and $T_{e}$ are the times the shock period began and ended, respectively, and $T_{d}$ is a variable delay time between onset of the shock onset and the onset of the slow effects; $C$ is the control (baseline) amplitude of the CAP, $a$ is the magnitude of the change in CAP amplitude at asymptote; and $\alpha$ is $1 /$ time constant. The parameters $T_{b}, T_{e}$, and $C$ were fixed. The other parameters $\left(\alpha, a\right.$ and $\left.T_{d}\right)$ were free and fit to the data with KALEIDAGRAPH software using a least-squares algorithm (Press et al., 1988). The fractional suppression of CAP associated with each shock burst $(S)$ was calculated as

$$
S=a\left(1-e^{-(I \alpha)}\right),
$$

where $I$ was the interval between shocks $(1.5 \mathrm{sec})$.

effect associated with each shock burst, and (3) the delay between shock onset and the onset of slow effects. As illustrated in Figure 9, typical data from the shock-burst paradigm could be well fit with these equations $(R=0.9)$. However, the description did not attempt to account for the overshoot in CAP following the shock period: recovery of CAP amplitude in the mathematical description was constrained to the preshock control values. This constraint resulted in an underestimation of the time constant in cases where the overshoot was large. In the case illustrated in Figure 9, the computed time constant was $33 \mathrm{sec}$, the magnitude of the slow effect was a $2.2 \%$ reduction of CAP amplitude with each shock burst, and the delay-to-effect onset was $11.6 \mathrm{sec}$. Across all nine cases analyzed, the average bestfit parameters ( \pm standard deviation) were time constant $=34.4$ $\sec ( \pm 8.8)$, suppression magnitude per shock burst $=1.92 \%$

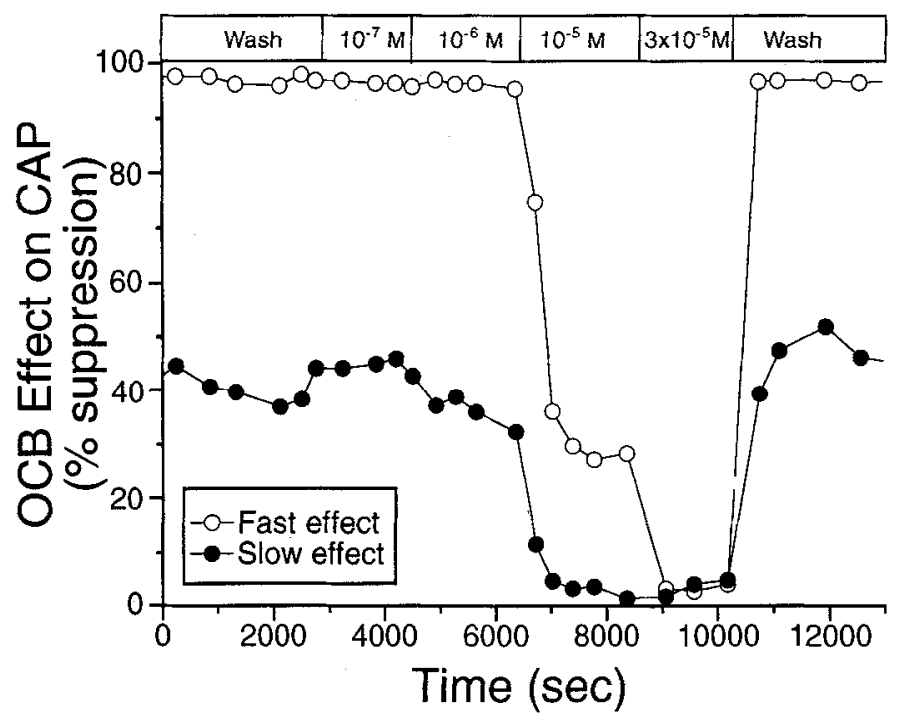

Figure 10. Perfusion of the scala tympani with several concentrations of the cholinergic antagonist decamethonium reduces the magnitude of fast and slow effects of OCB stimulation on CAP amplitudes. Stimuli were clicks presented at $20 \mathrm{~dB}$ above threshold. Fast and slow effects were quantified as described in the caption to Figure $8 B$. The boxes along the time axis indicate the concentrations of the drug delivered and the time periods during which the cochlea was perfused.

$( \pm 0.42)$, and delay $=8.5 \mathrm{sec}( \pm 5.5)$. For the same nine cases, the average fast effect was an $83 \%$ decrease in CAP amplitude. Thus, the slow-effect magnitude with each shock burst is about $2.3 \%$ that of the fast effect.

\section{Pharmacological analysis of fast and slow effects}

The fast effect of OCB stimulation on the CAP appears to be mediated by release of $\mathrm{ACh}$ onto outer hair cells (Eybalin, 1993). To assess whether the slow effect is also mediated by $\mathrm{ACh}$ and whether a different receptor is involved, the actions of a variety of cholinergic antagonists on fast versus slow effects were compared.

Fast and slow effects of OCB stimulation were measured using the paradigm illustrated in Figure $2 B$ while antagonists were perfused through scala tympani of the cochlea in increasing concentration. To illustrate how the effects of antagonists were measured, a case where the efferent effects were especially large is presented in Figure 10. Here, decamethonium, a nicotinic cholinergic antagonist, was perfused in concentrations ranging from $10^{-7}$ to $3 \times 10^{-5} \mathrm{M}$. There was little change in the magnitude of fast or slow effects until a concentration of $10^{-5} \mathrm{M}$ was reached. Blockade of both fast and slow effects appeared complete at concentrations of $3 \times 10^{-5} \mathrm{M}$. There was little effect of decamethonium on the control CAP amplitude (not illustrated). The blockade induced by decamethonium was completely reversed when the drug was washed out by perfusion of the cochlea with artificial perilymph.

Both slow and fast OCB effects were blocked by a wide variety of cholinergic antagonists, and all the drugs that blocked the fast effect also blocked the slow effect. Blockade was concentration dependent and generally reversible upon washing the scala tympani with artificial perilymph. For most drugs, the reversibility was immediate and complete; however, the blockade induced by curare took much longer to recover and was incomplete even after $1 \mathrm{hr}$ of washing, a finding consistent with that 

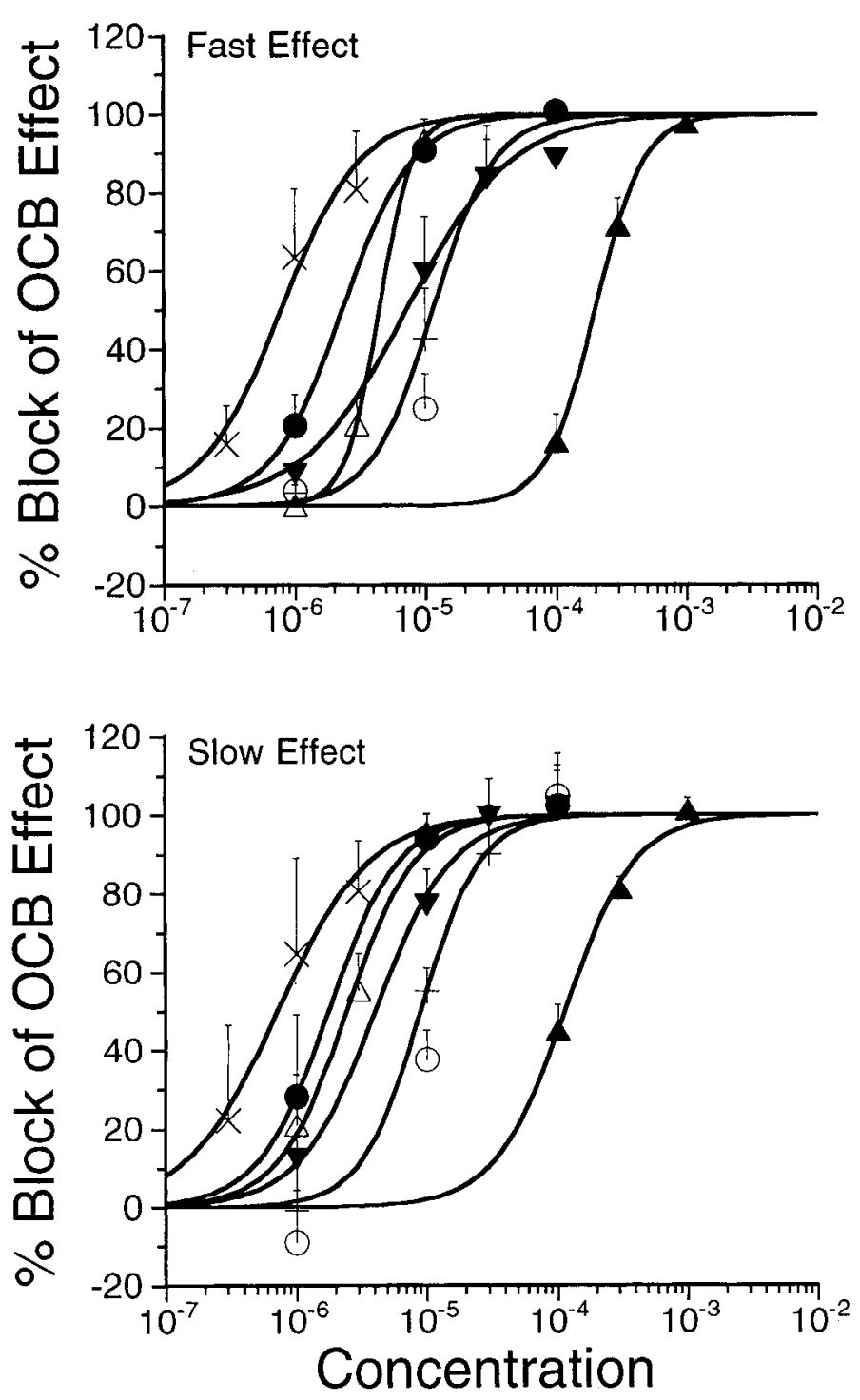

Figure 11. Blockade of the fast (top panel) and slow (bottom panel) effects of OCB stimulation on CAP amplitudes by a variety of pharmacological antagonists is dose related. Data points represent mean ( $t$ standard error) percentage blockade of the OCB effects. Sigmoidal curves were fit to the data as described in the methods. The symbols used for the antagonists are as follows: $\boldsymbol{O}$, curare; $\boldsymbol{\Delta}$, hexamethonium; $\boldsymbol{\nabla}$, decamethonium; $O$, atropine; $\triangle$, 4-DAMP; $\times$, strychnine; + , bicuculline. Dose-response curves were fitted to the data as described in Materials and Methods. The effects of atropine were investigated at too few concentrations to allow an accurate determination of the dose-response curve; however, the $\mathrm{EC}_{50}$ was estimated using the slope from the data for 4-DAMP. The dose-response data for decamethonium were obtained after omitting the data from one animal that had particularly noisy values due to a minimal slow effect. From the sigmoidal curve fits, a measure of the steepness of the dose-response curves (equivalent to the Hill coefficient) was determined tor each drug. Hill coefficients for the fast and slow effects, respectively, were as follows: strychnine, 1.42 , 1.24; curare, 1.59, 1.62; hexamethonium, 2.31, 1.63; bicuculline, $1.84,1.92$; DAMP, 3.3, 1.66; and decamethonium, 1.08, 1.49 .

of Housley and Ashmore (1991). Atropine and hexamethonium at high concentrations $(100 \mu \mathrm{M})$ produced a suppression of the control CAP amplitude, suggesting nonspecific actions were occurring at these high doses.

Sigmoid curves were fitted to the dose-response data for each antagonist on both the fast and slow effects (Figure 11). There

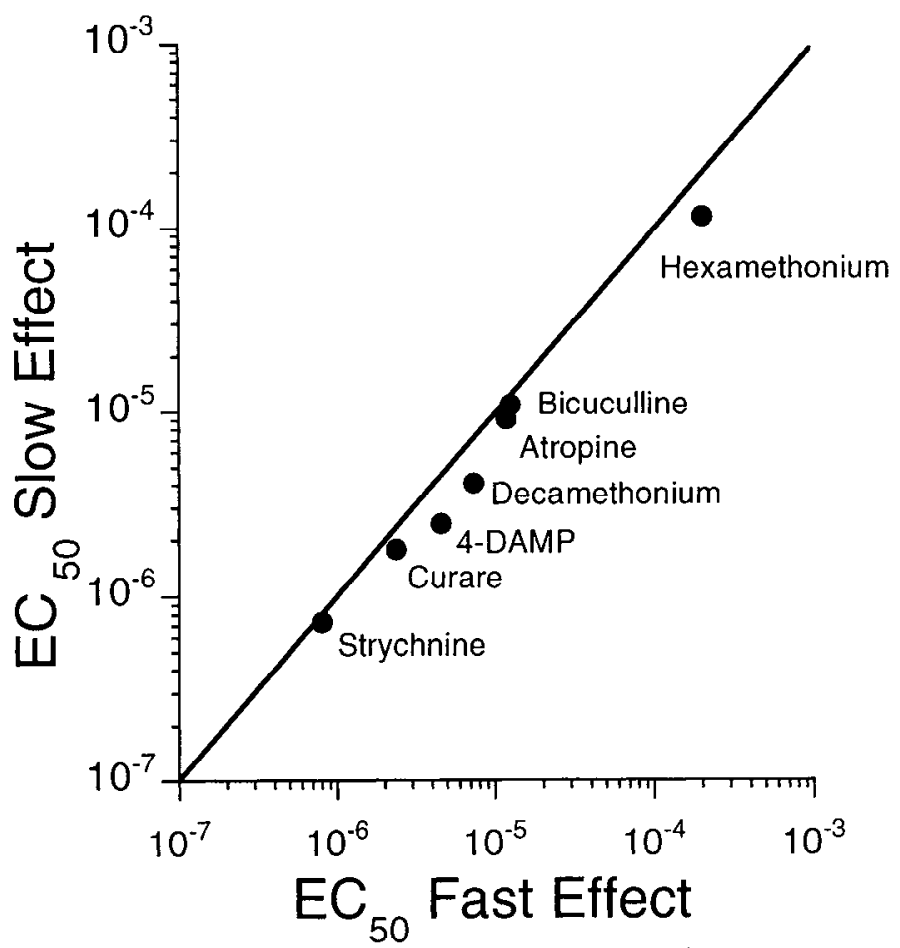

Figure 12. Comparison of the $\mathrm{EC}_{50}$ values for blockade of the fast and slow effects by the pharmacological agents illustrated in Figure 11. The diagonal line represents idealized equal $\mathrm{EC}_{50}$ values for the fast and slow effect. $\mathrm{EC}_{50}$ values were determined from the dose-response curves shown in Figure 11, as described in Materials and Methods.

was no clear separation in potencies of the nicotinic antagonists (curare, hexamethonium, and decamethonium; filled symbols) from the muscarinic (atropine and 4-DAMP; open symbols) or the nontraditional blockers (strychnine and bicuculline). Strychnine was the most potent agent tested, and curare, a nicotinic receptor blocker, was more potent than atropine, a muscarinic blocker. For both the slow and fast effects, the order of potencies was strychnine $>$ curare $>4$-DAMP $>$ decamethonium $>$ atropine $\geq$ bicuculline $>$ hexamethonium (based on the $\mathrm{EC}_{50} \mathrm{val}$ ues, i.e., the concentration producing half maximal blockade).

Although the drugs displayed a wide range of potencies, the concentrations required to block the slow effects were similar to those required to block the fast effects. When the $\mathrm{EC}_{50}$ values for the fast effect blockade werc plotted against the $\mathrm{EC}_{50}$ for the slow effect blockade for each drug (Fig. 12), the two sets of $\mathrm{FC}_{50}$ values were well correlated. All the drugs blocked the slow effect at a slightly lower concentration than the fast effect.

\section{Discussion}

Physiological mechanism of slow effect

There is considerable evidence that fast effects of OCB stimulation are mediated by myelinated fibers of the medial olivocochlear system (MOC) synapsing on outer hair cells rather than the unmyelinated LOC system targeting the afferent terminals under inner hair cells. Three of the strongest arguments favoring this view are (1) that peripheral effects seen when stimulating at the floor of the IVth ventricle are.identical to those seen when stimulating near the cells of origin of the MOC system (Guinan et al., 1983; Gifford and Guinan, 1987), (2) that the dependence of these suppressive cffects on shock rate (as illustrated in Fig. $8 B$ ) is not consistent with what is known about the electrical 
excitability of unmyelinated fiber pathways (which tend to respond best to significantly lower shock rates), and (3) that the suppression of CAP is associated with an enhancement of CM, which is well explained by postulating an MOC-mediated increase in the conductance of the outer hair cells.

Observations in the present study allow two of these three arguments to be made for a similar association between slow effects and the MOC pathway to outer hair cells: (1) slow effect magnitude varies with OCB shock rate in a way similar to that of fast effects (Fig. 8B), and (2) slow CAP suppression is also associated with slow CM enhancement (Fig. 7). No data are available comparing the extent to which slow effects can be generated by direct stimulation in the region of the cells of origin of MOC versus LOC systems. However, the present study also provides evidence that fast and slow effects are mediated by the same cholinergic receptor, given the similarity in pharmacological profiles for blockade of the two effects with a wide variety of cholinergic antagonists (Figs. 11, 12; discussed below).

Several other potential mechanisms for the OCB slow effects can be ruled out. The disappearance of slow effects upon OCB section provides strong evidence that the phenomenon is not due to direct influence of the shocks on the cochlca. Thesc data also argue against the possibility that the shocks are affecting cochlear blood flow by activation of autonomic fiber pathways, since the known pathways for vascular innervation of the cochlea would not be interrupted by these cuts (Hozawa et al., 1989). Furthermore, the cochlear vasculature is innervated by sympathetic adrenergic fibers (Spoendlin and Lichtensteiger, 1967), yet slow effects are completely blocked by perfusion of the scala tympani with cholinergic antagonists. The hypothesis that the slow effect is due to increased OC fiber activity with prolonged electrical stimulation is ruled out by the persistence of the lingering suppression, associated with the slow effects, when the OCB was sectioned immediately following the shocks (Fig. 4C). The fact that slow effects were demonstrable in cases in which both middle-ear muscles had been surgically inactivated eliminates this feedback pathway as a source of the phenomenon.

A slow amplitude change has been demonstrated in the distortion-product otoacoustic emissions (Brown, 1988) and is thought to be mediated by a GABAergic component of the OC system (Kirk and Johnstone, 1993). However, the slow changes in otoacoustic emissions differed from the slow effect described in the present study in having, (1) a slower time course, (2) a distribution toward lower frequencies, and (3) a pharmacological insensitivity to strychnine, thus suggesting that they are not mediated by the same process.

\section{Molecular mechanisms of slow versus fast effects}

The present study's in vivo pharmacological experiments support the prevailing notion that the receptor mediating the effects of OCB stimulation has a unique pharmacological profile, in that it can be blocked by nicotinic and muscarinic antagonists, as well as strychnine and bicuculline. The order of potencies of these antagonists determined by a comparison of their $\mathrm{EC}_{50}$ values is in good agreement with the results of Kujawa et al. (1994) on the pharmacology of contralateral noise suppression of otoacoustic emissions (a phenomenon mediated by MOC activation). The concentrations of antagonists needed to block the soundevoked effects of the MOC system reported by Kujawa et al. (1994) are lower than those required to block the effects of electrical stimulation observed in our study. This result is expected since electrical stimulation produces a more massive release of
ACh (as evidenced by larger CAP suppressions), and the antagonists are competing with $\mathrm{ACh}$ for the receptor.

The most parsimonious interpretation of the pharmacological data in the present study is that both fast and slow effects are mediated by the same postsynaptic receptor. For the wide variety of antagonists tested, potencies (measured by $\mathrm{EC}_{50} \mathrm{~s}$ ) were similar on both the fast and slow effects. The observation that both fast and slow effects were associated with increases in the CM suggests that both involve increased conductance at the outer hair cell. Studies on isolated outer hair cells from guinea pigs (Housley and Ashmore, 1991; Kakehata et al., 1993; Erostegui et al., 1994) and chicks (Fuchs and Morrow, 1992) have shown that application of ACh produces, within 50-100 msec, a hyperpolarizing potassium current that is due to the activation of calcium-activated potassium channels. These channels are activated by a small, transient inward current carried in part by calcium that is associated with binding of $\mathrm{ACh}$ to the receptor. Thus, in some sense, the fast effect can be considered to be mediated by a fast second messenger (calcium).

A good candidate for the ACh receptor on outer hair cells is an $\alpha 9$ subunit recently cloned by Elgoyhen et al. (1994). Pharmacologically, the homomeric $\alpha 9$ receptor is unique in that it is not activated by nicotine, and is blocked reversibly by $\alpha$-bungarotoxin, curare, atropine, and strychnine. The order of potency of these antagonists for blocking the $\alpha 9$ receptor is the same as that for the cholinergic receptor in the cochlea. Homo-oligomers of $\alpha 9$ seem to be permeable to calcium. All these characteristics match those of the $\mathrm{ACh}$ receptor on the outer hair cell (Housley and Ashmore, 1991; Kakehata et al., 1993; Erostegui et al., 1994; Kujawa et al., 1994). In addition, Elgoyhen et al. (1994) show, with in situ hybridization studies, the presence of $\alpha 9$ transcripts in the rat inner and outer hair cells.

If we presume that the postsynaptic receptor transducing the signal delivered by $\mathrm{ACh}$ is the same for both the fast and slow effects, then there must be distinct intracellular mechanisms mediating the two effects. The mathematical description presented in the results suggests that the slow effect cannot be explained as a cumulative buildup of residual fast effect. A decay time constant almost 1000 times that of classic fast effects is needed for any substantial buildup to occur. It is plausible that the calcium entry associated with the fast effect is also responsible for generating the slow effect by either directly activating distant calcium-activated potassium channels or indirectly inducing release of calcium from intracellular stores to increase free calcium concentration and then activate calcium-sensitive potassium channels. The subsynaptic cisternae of the outer hair cell, located at the efferent synapse, and perhaps comparable in function to the endoplasmic or sarcoplasmic reticulum, is a likely calcium release site.

Another possible mechanism for generation of the slow effect, based upon in vitro studies on isolated hair cells (Kakehata et al., 1993; Yoshida et al, 1994), involves activation of a G-protein and the use of inositol triphosphate as a mediator. It seems unlikely, though, that a G-protcin-linked ACh receptor on the outer hair cell would have the same unusual pharmacology as the ionotropic $\mathrm{ACh}$ receptor, given that the two classes of receptors have distinctively different structures and have little structural homology. That a single $\mathrm{ACh}$ receptor might have both pore-forming and $\mathrm{G}$-protein binding properties also seems unusual, although mixed nicotinic/muscarinic receptors are postulated to exist in cullured mouse myotubes (Giovanelli, 1991), and bovine chromaffin cells (Shirvan, 1991). An understanding 
of the mechanisms for generation of the slow effect awaits further study.

If the slow effect is mediated by the same receptor as the fast effect, but by different intracellular mechanisms, one must suggest that those intracellular mechanisms are differentially distributed among hair cells along the length of the cochlea, since the fast effect has a frequency distribution that parallels the innervation of the organ of Corti by the MOC pathway, whereas the slow effect is restricted to a higher frequency region (Fig. $8 C$ ). There are no known anatomical data, either with respect to hair cell ultrastructure or distribution of immunohistochemically distinct classes of OC terminals, that can (at present) provide a ready explanation for this differential distribution of $\mathrm{OC}$ effects along the cochlear spiral.

\section{Possible functional significance of $O C$ slow effects}

Although the present study does not directly demonstrate that slow effects are elicited when the OCB is activated acoustically, there is every reason to believe that they are. In the continuousshock paradigm, the shock rate was typically $150 / \mathrm{sec}$, which is somewhat higher than the sound-evoked discharge rates in MOC efferents seen when stimulus level reaches $90 \mathrm{~dB}$ SPL (Liberman, 1988; Brown, 1989). Thus, both fast and slow effects of sound-evoked activity might be somewhat smaller than those reported here; however, they also might decrement less rapidly given the overall decrease in ensemble MOC discharge rate.

If $\mathrm{OC}$ slow effects are restricted in all animals to cochlear frequency regions above $10 \mathrm{kHz}$, this clearly limits their potential importance to cochlear function in general. However, recent experiments with acoustic overstimulation suggest that the cochlear protection associated with activation of the $\mathrm{OC}$ system (Rajan, 1988) may actually arise from slow rather than fast effects (Reiter and Liberman, 1994). The cvidence for this association is circumstantial at present: (1) that protection is only demonstrable when the region of maximum threshold shift falls within the cochlear regions where slow effects are large, and (2) that protective effects disappear when the duration of the OC activation is increased such that slow effects are extinguished. If the protective effects are, indeed, mediated by the kind of slow $O C$ effect described here, then the analysis presented here suggests that this kind of cochlear protection is based on secondmessenger mediated changes in the function of outer hair cells.

\section{References}

Bobbin RP, Konishi T (1974) Action of cholinergic and anticholinergic drugs at the crossed olivo-cochlear bundle hair-cell junction. Acta Otolaryngol (Stockh) 77:55-65.

Brown AM (1988) Continuous low level sound alters cochlear mechanics: an efferent effect? Hear Res 34:27-38.

Brown MC (1987) Morphology of labeled efferent fibers in the guinea pig cochlea. J Comp Neurol 260:605-618.

Brown MC (1989) Morphology and response properties of single olivocochlear fibers in the guinea pig. Hear Res 40:93-110.

Brown MC, Nuttall AL, Masta RI (1983) Intracellular recordings from cochlear inner hair cells: effects of stimulation of the crossed olivocochlear efferents. Science 222:69-72.

Dallos P (1973) Cochlear potentials and cochlear mechanics. In: Basic mechanisms in hearing (Moller AR, ed), pp 335-372. New York: Academic.

Desmedt JE (1962) Auditory-evoked potentials from cochlea to cortex as influenced by activation of the efferent olivo-cochlear bundle. J Acoust Soc Am 34:1478-1496.

Elgoyhen AB, Johnson DS, Boulter J, Vetter DE, Heinemann S (1994) Alpha 9: an acetylcholine receptor with novel pharmacological properties expressed in rat cochlear hair cells. Cell 79:705-715.

Erostegui C, Norris CH, Bobbin RP (1994) In vitro pharmacologic characterization of a cholinergic receptor on outer hair cells. Hear Res $74: 135-147$.

Eybalin M (1993) Neurotransmitters and neuromodulators of the mammalian cochlea. Physiol Rev 73:309-373.

Fex J (1959) Augmentation of cochlear microphonic by stimulation of efferent fibers to the cochlea. Acta Otolaryngol (Stockh) 50:540541.

Fex J (1967) Efferent inhibition in the cochlea related to hair-cell dc activity: study of postsynaptic activity of the crossed olivocochlear fibers in the cat. J Acoust Soc Am 41:666-675.

Fuchs PA, Murrow BW (1992) Cholinergic inhibition of short (outer) hair cells of the chick's cochlea. J Neurosci 12:800-809.

Galambos R (1956) Suppression of auditory nerve activity by stimulation of efferent fibers to cochlea. J Neurophysiol 19:424-437.

Gifford ML, Guinan JJ Jr (1983) Effects of crossed-olivocochlearbundle stimulation on cat auditory nerve fiber responses to tones. J Acoust Soc Am 74: 115-123.

Gifford ML, Guinan JJ Jr (1987) Effects of electrical stimulation of medial olivocochlear neurons on ipsilateral and contralateral cochlear responses. Hear Res 29:179-194.

Giovanelli A, Grassi F, Mattei E, Mileo AM, Eusebi F (1991) Acetylcholine induces voltage-dependent increase of cytosolic calcium in mouse myotuhes. Proc Natl Acad Sci USA 88:10069-10073.

Guinan JJ Jr, Gifford ML (1988) Effects of electrical stimulation of efferent olivocochlear neurons on cat auditory-nerve fibers. III. Tuning curves and thresholds at CF. Hear Res 37:29-46.

Guinan JJ Jr, Warr WB, Norris BE (1983) Differential olivocochlear projections from lateral versus medial zones of the superior olivary complex. J Comp Neurol 221:358-370.

Guth PS, Norris CH, Bobbin RP (1976) The pharmacology of transmission in the peripheral auditory system. Pharmacol Rev 28:95125.

Housley GD, Ashmore JF (1991) Direct measurement of the action of acetylcholine on isolated outer hair cells of the guinea pig cochlea. Proc R Soc Lond [Biol] 244:161-167.

Hozawa K, Kimura RS, Takasaka T (1989) Sympathetic nervous system in guinea pig cochlea. Ear Res Jpn 20:111-113.

Kakehata S, Nakagawa T, Takasaka T, Akaike N (1993) Cellular mechanism of acetylcholine induced response in dissociated outer hair cells of guinea-pig cochlea. J Physiol (Lond) 463:227-244.

Kiang NYS, Watanabe T, Thomas EC, Clark LF (1965) Discharge patterns of single fibers in the cat's auditory nerve. Cambridge, MA: MIT Press.

Kimura R, Wersall J (1962) Termination of the olivocochlear bundle in relation to the outer hair cells of the organ of Corti in guinea pig. Acta Otolaryngol (Stockh) 55:11-32.

Kirk DL, Johnstone BM (1993) Modulation of $f_{2}-f_{1}$ : evidence for a GABA-ergic efferent system in apical cochlea of the guinea pig. Hear Res 67:20-34.

Kujawa SG, Glattke TJ, Fallon M, Bobbin RP (1994) A nicotiniclike receptor mediates suppression of distortion product otoacoustic emissions by contralateral sound. Hear Res 74:122-134.

Liberman MC (1980) Efferent synapses in the inner hair cell area of the cat cochlea: an electron microscopic study of serial sections. Hear Res 3:189-204.

Liberman MC (1988) Physiology of cochlear efferent and afferent neurons: direct comparisons in the same animal. Hear Res 34:179192.

Liberman MC (1990) Effects of chronic cochlear de-efferentation on auditory-nerve response. Hear Res 49:209-224.

Liberman MC, Dodds LW, Pierce S (1990) Afferent and efferent innervation of the cat cochlea: quantitative analysis with light and electron microscopy. J Comp Neurol 301:443-460.

Patneau DK, Mayer ML (1990) Structure-activity relationships for amino acid transmitter candidates acting at $N$-methyl-D-aspartate and quisqualate receptors. J Neurosci 10:2385-2399.

Press WH, Flannery BP, Teukolsky SA, Vetterling WT (1988) Numerical recipes in C. Cambridge: Cambridge UP.

Rajan R (1988) Effect of electrical stimulation of the crossed olivocochlear bundle on temporary threshold shifts in auditory sensitivity. I. Dependence on electrical stimulation parameters. J Neurophysiol 60:549-568.

Reiter ER, Liberman MC (1995) Efferent mediated protection from acoustic overexposure: relation to "slow" effects of olivocochlear stimulation. J Neurophysiol 73:506-514. 
Russell IJ, Sellick PM (1983) Low-frequency characteristics of intracellularly recorded receptor potentials in guinea-pig cochlear hair cells. J Physiol (Lond) 338:179-206.

Seguela P, Wadiche J, Dineley-Miller K, Dani JA, Patrick JW (1993) Molecular cloning, functional properties and distribution of rat brain $\alpha 7$ : a nicotinic cation channel highly permeable to calcium. J Neurosci 13:596-604.

Shirvan MH, Pollard HB, Heldman E (1991) Mixed nicotinic and muscarinic features of cholinergic receptors coupled to secretion in bovine chromaffin cells. Proc Natl Acad Sci USA 88:4860-4864.

Smith CA (1961) Innervation pattern of the cochlea. The internal hair cell. Ann Otol Rhinol Laryngol 70:504-527.

Smith CA, Sjostrand FS (1961) Structure of the nerve endings on the external hair cells of the guinea pig cochlea as studied by serial sections. J Ultrastruct Res 5:523-556.

Spocndlin H, Lichtensteiger W (1967) The sympathetic nerve supply to the inner ear. Arch Klin Exp Ohr Nas Kehlkopfheilk 189:346.

Teas DC, Konishi T, Nielsen DW (1970) Electrophysiological studies on the spatial distribution of the crossed olivocochlear bundle along the guinea pig cochlea. J Acoust Soc Am 51:1256-1264.

Warr WB (1992) Organization of olivocochlear efferent systems in mammals. In: The mammalian auditory pathway: neuroanatomy (Webster DB, Popper AN, Fay RR, eds), pp 410-448. New York: Springer.

Warr WB, Guinan JJ Jr (1979) Efferent innervation of the organ of Corti: two separate systems. Brain Res 173:152-155.

White JS, Warr WB (1983) The dual origins of the olivocochlear bundle in the albino rat. J Comp Neurol 219:203-214.

Wiederhold ML (1970) Variations in the effects of electric stimulation of the crossed olivocochlear bundle on cat single auditorynerve-fiber responses to tone bursts. J Acoust Soc Am 48:966-977.

Wiederhold ML, Kiang NYS (1970) Effects of electric stimulation of the crossed olivocochlear bundle on single auditory-nerve fibers in the cat. J Acoust Soc Am 48:950-965.

Wiederhold ML, Peake WT (1966) Efrerent inhibition of auditorynerve responses: dependence on acoustic-stimulus parameters. J Acoust Soc Am 40:1427-1430. 